\title{
Health-related quality of life in women with breast cancer: a review of measures
}

\author{
Maribel Salas ${ }^{1,2^{*}}$, Margaret Mordin ${ }^{3}$, Colleen Castro $^{4} \mathbb{C}^{0}$, Zahidul Islam ${ }^{1}$, Nora Tu ${ }^{1}$ and Michelle D. Hackshaw ${ }^{1}$
}

\begin{abstract}
Background: To identify and describe the breast cancer-specific health-related quality of life (HRQoL) instruments with evidence of validation in the breast cancer population for potential use in patients treated for breast cancer (excluding surgery).

Methods: We conducted a systematic literature review using PubMed, Embase, and PsycINFO databases to identify articles that contain psychometric properties of HRQoL instruments used in patients with breast cancer. Relevant literature from January 1, 2009, to August 19, 2019, was searched. Articles published in English that reported psychometric properties (reliability, validity) of HRQoL instruments were identified.

Results: The database search yielded 613 unique records; 131 full-text articles were reviewed; 80 articles presented psychometric data for instruments used in breast cancer (including generic measures). This article reviews the 33 full articles describing psychometric properties of breast cancer-specific HRQoL instruments: EORTC QLQ-C30, EORTC QLQ-BR23, FACT-B, FBSI, NFBSI-16, YW-BCI36, BCSS, QuEST-Br, QLICP-BR, INA-BCHRQoL, and two newly developed unnamed measures, one by Deshpande and colleagues (for use in India) and one by Vanlemmens and colleagues (for use among young women and their partners). The articles that described the EORTC QLQ-C30, QLQ-BR23, and FACT-B centered on validating translations, providing additional support for content validity, and demonstrating acceptability of electronic patient-reported outcome administration. Psychometric properties of the measures were acceptable. Several new measures have been developed in Asia with an emphasis on development on cultural relevance/sensitivity. Others focused on specific populations (i.e., young women with breast cancer).

Conclusions: Historically, there have been limited options for validated measures to assess HRQoL of patients with breast cancer. A number of new measures have been developed and validated, offering promising options for assessing HRQoL in this patient population. This review supports the reliability and validity of the EORTC QLQ-C30 and FACT$B$; new translations and electronic versions of these measures further support their use for this population.
\end{abstract}

Keywords: PROMs, Breast cancer

\section{Background}

Patient-reported outcomes (PROs) are defined as a "measurement of any aspect of a patient's health status that comes directly from the patient (i.e., without the interpretation of the patient's responses by a physician

\footnotetext{
*Correspondence: msalas@dsi.com

${ }^{1}$ Epidemiology, Clinical Safety and Pharmacovigilance, Daiichi Sankyo,

Inc., 211 Mount Airy Road, 1A-453, Basking Ridge, NJ 07920, USA

Full list of author information is available at the end of the article
}

or anyone else)" [1]. Patient-reported outcome measures (PROMs) provide an opportunity for patients to indicate the impact of a disease and its treatment on their lives. Health-related quality of life (HRQoL) represents a patient's physical, psychological, and social response to disease and therapy and is one type of PRO [2]. PROs can provide additional information to help with treatment approval, reimbursement, and selection/dosing decisions; management of medication side effects; health monitoring; and patient-provider decision-making. 
Breast cancer is the most commonly occurring cancer in women, with an estimated 2 million new cancer cases diagnosed globally in 2018 [3]. Advanced breast cancer has been described as a generally incurable, yet treatable disease, and the primary goals of treatment are to reduce symptom burden, maintain quality of life (QoL), and prolong survival $[4,5]$. Treatment for patients with advanced disease includes neoadjuvant chemotherapy, surgery, postsurgical radiation therapy, and systemic adjuvant therapy (including hormone therapy for those with hormone receptor-positive breast cancers). Understanding the impact of treatment on patients' HRQoL outside clinical trials can provide useful information for patients and clinicians in making treatment decisions.

Several PROMs have been used to assess patients with breast cancer. PROMs are questionnaires that capture patients' feelings and functioning in a structured manner and consist of items and corresponding response options; When developed and validated according to international guidelines, PROMs can provide reliable and valid patient assessment.

A systematic literature review by Nguyen et al. [6] indicated that the European Organization for Research and Treatment of Cancer (EORTC) Breast Cancer-Specific Quality of Life Questionnaire-23 item (QLQ-BR23) and the Functional Assessment of Cancer Therapy-Breast (FACT-B) are the only HRQoL questionnaires that have been developed specifically for patients with breast cancer facing different disease stages and treatments. Both tools act as supplements to their general cancer questionnaires, the EORTC Quality of Life Questionnaire, Version 3.0 (QLQ-C30) and the FACT-G, respectively. Given recent developments in breast cancer treatment, we sought to determine whether additional valid and reliable HRQoL measures are available in the public domain. Specifically, we aimed to identify breast cancer-specific HRQoL measures with evidence of validation in the breast cancer population for potential use in patients underwent systemic treatment for breast cancer (excluding surgery and radiotherapy).

As HRQoL measures are focused on patients' overall health and well-being, regional characteristics and traditions may be included. This review focused on identifying HRQoL measures regardless of whether or not they were region specific.

\section{Methods}

\section{Literature search}

The literature review was conducted on August 19, 2019, in the PubMed, Embase, and PsycINFO databases. Table 1 presents the search strategy used for PubMed; the key words used were translated for each of the individual databases. The search focused on the past 10 years (January 1,2009-August 19, 2019), was limited to publications written in English, and excluded commentaries, letters to editors, editorials, book chapters and case reports because they did not contain detailed information on the psychometric properties of the instruments.

Table 1 PubMed Search Strategy

\begin{tabular}{|c|c|c|}
\hline Search No. & Search Terms & No. of Articles \\
\hline \multicolumn{3}{|l|}{ Disease } \\
\hline$\# 1$ & $\begin{array}{l}\text { "Breast Neoplasms"[Majr] OR breast neoplasm*[Title] OR breast cancer*[Title] OR breast carcinoma*[Title] OR breast } \\
\text { tumor*[Title] OR breast tumour*[Title] OR mammary cancer*[Title] OR mammary carcinoma*[Title] OR mammary } \\
\text { neoplasm*[Title] OR mammary tumor*[Title] OR mammary tumour*[Title] OR"cancer of the breast"[Title] OR breast } \\
\text { malignan*[Title] OR mammary malignan*[Title] }\end{array}$ & 123,621 \\
\hline \multicolumn{3}{|c|}{ Quality of life } \\
\hline \#2 & $\begin{array}{l}\text { \#1 AND (("Quality of Life"[Majr] OR "quality of life"[Title] OR "life quality"[Title/Abstract] OR QoL[Title/Abstract] OR } \\
\text { hrql[Title/Abstract] OR hrqol[Title/Abstract] OR "EORTC-QLQ-C30"[Title/Abstract] OR "FACT-B"[Title/Abstract]) } \\
\text { NOT ("Quality-Adjusted Life Years"[Mesh] OR "quality adjusted life year"[Title] OR "quality adjusted life years"[Title] } \\
\text { OR QALY[Title] OR health utilit*[Title] OR HUI[Title] OR "standard gamble"[Title] OR "time trade off"[Title] OR "time } \\
\text { tradeoff"[Title] OR TTO[Title])) }\end{array}$ & 2260 \\
\hline \multicolumn{3}{|l|}{ Validity } \\
\hline \#3 & $\begin{array}{l}\text { \#2 AND ("Psychometrics"[Mesh] OR valid*[Text Word] OR reliable*[Text Word] OR reliability[Text Word] OR } \\
\text { psychometric*[Text Word] OR (concurrent[Text Word] AND validity[Text Word]) OR (divergent[Text Word] AND } \\
\text { validity[Text Word]) OR responsiveness[Text Word] OR responder*[Text Word] OR correlation coefficient*[Text Word] } \\
\text { OR correlation co-efficient* [Text Word] }\end{array}$ & 311 \\
\hline \multicolumn{3}{|l|}{ Exclusions } \\
\hline \#4 & "Animals"[Mesh] NOT"Humans"[Mesh] & $1,144,986$ \\
\hline \#5 & "Comment"[Publication Type] OR "Letter"[Publication Type] OR "Editorial"[Publication Type] & 753,935 \\
\hline \multicolumn{3}{|l|}{ Totals } \\
\hline$\# 6$ & (\#3 NOT (\#4 OR \#5)) & 310 \\
\hline
\end{tabular}




\section{Literature review}

Unique records that were identified across the three databases were reviewed in accordance with prespecified inclusion criteria. Studies were required to include patients (aged $\geq 18$ years) with breast cancer who were treated with a pharmaceutical intervention and to assess a psychometric property of an HRQoL-focused PROM. Psychometric properties of interest included reliability (internal consistency, Cronbach alpha, test-retest), validity (content, convergent, divergent), and responsiveness. Psychometric properties for different modes of administration (e.g., electronic PRO [ePRO]) or for translations were included. Reasons for exclusion were populations receiving surgery or radiation, studies focused on HRQoL of treatment efficacy only, and studies only considering caregiver burden. References of relevant review articles were reviewed for any pertinent articles not identified in the original search. Two investigators reviewed the abstracts and selected abstracts that fulfilled the inclusion criteria. Any disagreement among investigators was discussed and final decision was done based on consensus.

During level 1 screening (titles and abstracts), studies that did not meet criteria were excluded. Full texts of included studies were reviewed (level 2 screening) using the same relevance criteria applied at level 1. Upon completion of level 2, an additional criterion was added to focus the review on breast cancer-specific HRQoL instruments only.

Information regarding reliability (internal consistency, Cronbach alpha, test-retest) and validity (content, convergent, divergent) were extracted from the studies. These psychometric properties were analyzed in accordance with prespecified thresholds of significance (e.g., Cronbach alpha $>0.7$ ). In addition, item content of the instruments was reviewed.

\section{Results}

Figure 1 summarizes the literature review, which identified 613 unique records for level 1 screening, of which 131 full-text articles were reviewed; 80 articles presented psychometric properties for identified PROMs used in breast cancer. This review focuses on the 33 that described psychometric properties of breast cancer-specific HRQoL instruments.

Psychometric properties of 12 PROMs were identified: EORTC QLQ-C30, EORTC QLQ-BR23, FACT-B, Functional Assessment of Cancer Therapy-Breast Symptom Index (FBSI), National Comprehensive Cancer NetworkFunctional Assessment of Cancer Therapy-Breast Cancer Symptom Index-16 (NFBSI-16), Young Women with Breast Cancer Inventory (YW-BCI36), Breast Cancer
Symptom Scale (BCSS), QuEST Breast Cancer Questionnaire (QuEST-Br), Quality of Life Instruments for Cancer Patients-Breast Cancer (QLICP-BR), Indonesian Breast Cancer Health-Related Quality of Life (INA-BCHRQoL), and two new unnamed measures [7-9]. For each identified PROM, Table 2 provides an overview of the measure's purpose, the domains assessed and the number of items. Table 3 provides an overview of concepts addressed for each PROM. Table 4 provides an overview of the psychometric articles (instrument, objective, population), and Table 5 provides psychometric qualities of the identified instruments.

\section{Comparison of item content}

A review of the item content of the identified measures reveals variability in the content that each assesses (Table 3). Most of the PROMs assess not only breast cancer symptoms, but the physical and emotional aspects of the disease. Breast cancer-specific symptoms appear not to be included in INA-BCHRQoL, YW-BCI36, and the new measures [7-9]. Physical and emotional or social functioning are included in the QLQ-C30/QLQBR23, FACT-B, FBSI, NFBSI-16, QuEST-Br, QLICP-BR, whereas other concepts are addressed within only one or two PROMs. For example, sexual function is included in the QLQ-BR23, but no other PROM; body image is only included in the QLQ-BR23 and the YW-BCI36. Vanlemmens and colleagues' measure for young women (<45years of age) is focused not only on the patient with breast cancer but also on her partner and their relationship (i.e., couple cohesion, managing children/everyday life) [8]. Regarding the financial impact of living with breast cancer, only the measure by Vanlemmens et al. [8] and the YW-BC136 include this concept. Approximately two thirds of the identified articles (22/33) focused on the EORTC QLQ-C30, EORTC QLQ-BR23, or the FACT-B.

\section{EORTC QLQ-C30 and EORTC QLQ-BR23}

Fourteen publications provided additional psychometric validation of the EORTC measures (QLQ-C30 and QLQ-BR23) (Table 4). Of these, eight were focused on validation of the EORTC modules in new languages (e.g., Chinese [23], Arabic [10, 11, 14, 20], Mexican-Spanish [13] or confirmation that the measures was understood by or used in larger populations (Brazil [16], Albania [17], Singapore [20]); two articles presented additional confirmation of content validity $[18,19]$, one article tested the replicability of cutoff scores [19], and three demonstrated acceptability of the measures in ePRO platforms $[15,21$, 22].

Internal consistency was assessed using the Cronbach alpha coefficient for translations. The breast symptoms scale for several translations (Chinese [23], Arabic [14], 


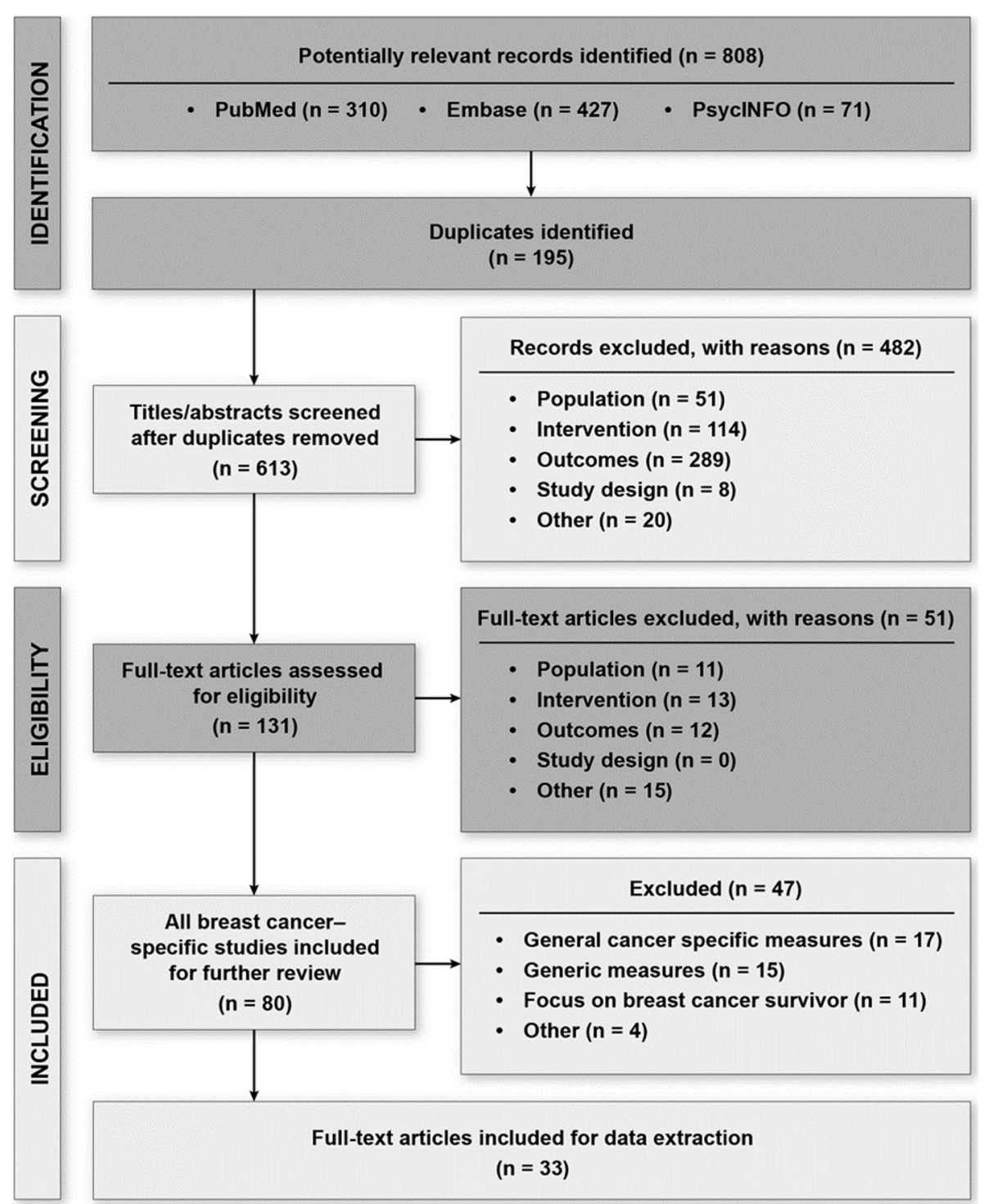

Fig. 1 PRISMA Diagram

and Mexican-Spanish [13]) was below 0.70; otherwise reliability of the QLQ-BR23 translations met established criteria (Table 5). Test-retest reliability was also established for the Arabic version [10]. Various methods were used to evaluate the validity of the translations, including multitrait scaling and known-groups comparisons. Itemconvergent validity was demonstrated (i.e., exceeding the 0.40 criterion) $[14,17,23]$. The questionnaires differentiated patients with lymphedema from those without [29], differentiated patients with early stage breast cancer versus those with locally advanced breast cancer [11, 13], and were responsive to changes following treatment [13]. Additional content validity for signs and symptoms was evaluated by testing the correlation between reported adverse events and responses to the QLQ-C30 [18].

Bjelic-Radisic et al. [12] evaluated whether updates in breast cancer treatment necessitate updating the EORTC QLQ-BR23, which was developed in 1996. A literature review and interviews with patients and health care providers suggest that additional concepts were missing. The new items contain two multi-item scales: target symptom scale (20 items) and satisfaction scale ( 2 items). The target symptom scale can be further divided into three subscales: endocrine therapy scale, endocrine sexual scale, and skin/mucosa scale. Further psychometric validation is underway. 


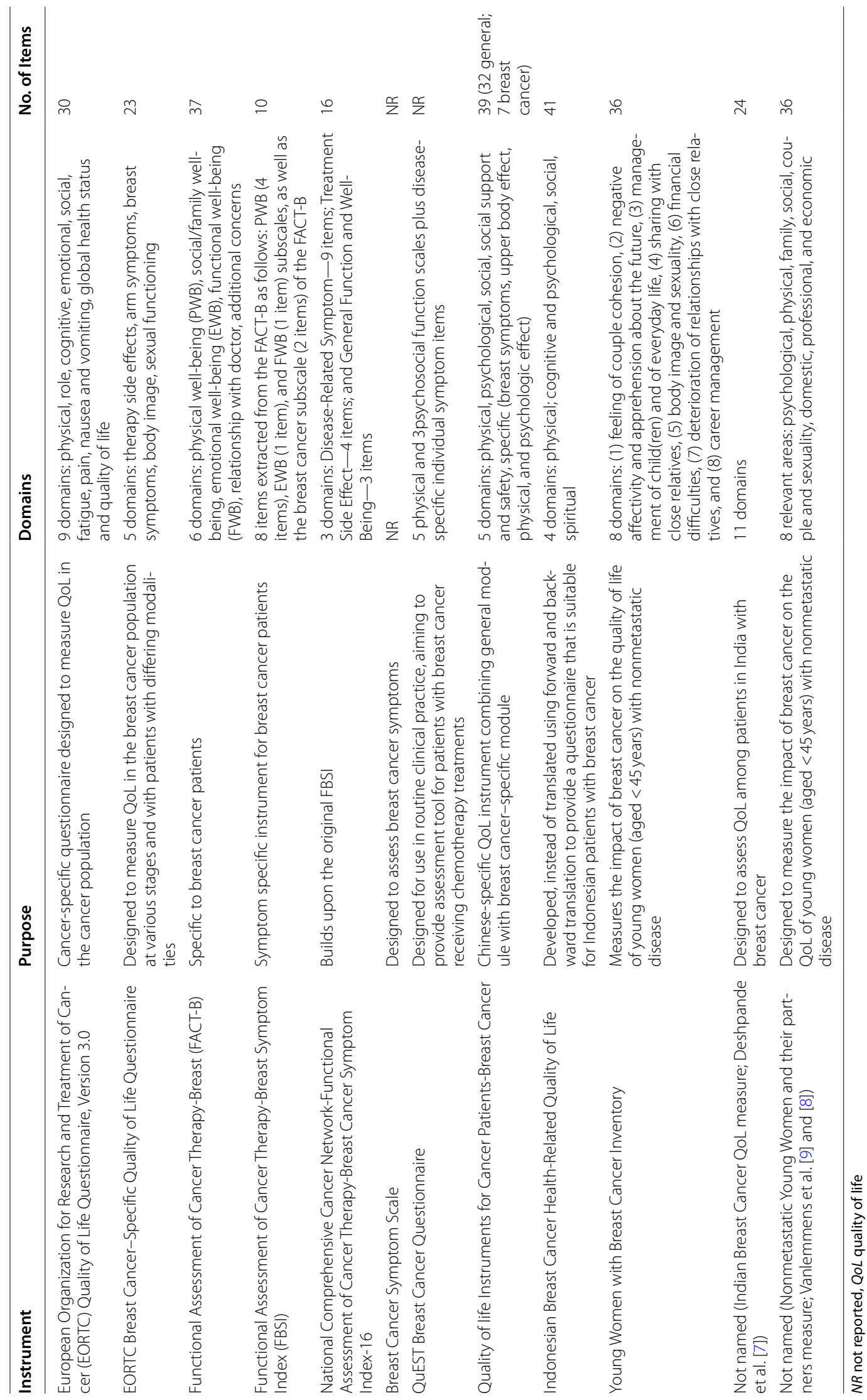




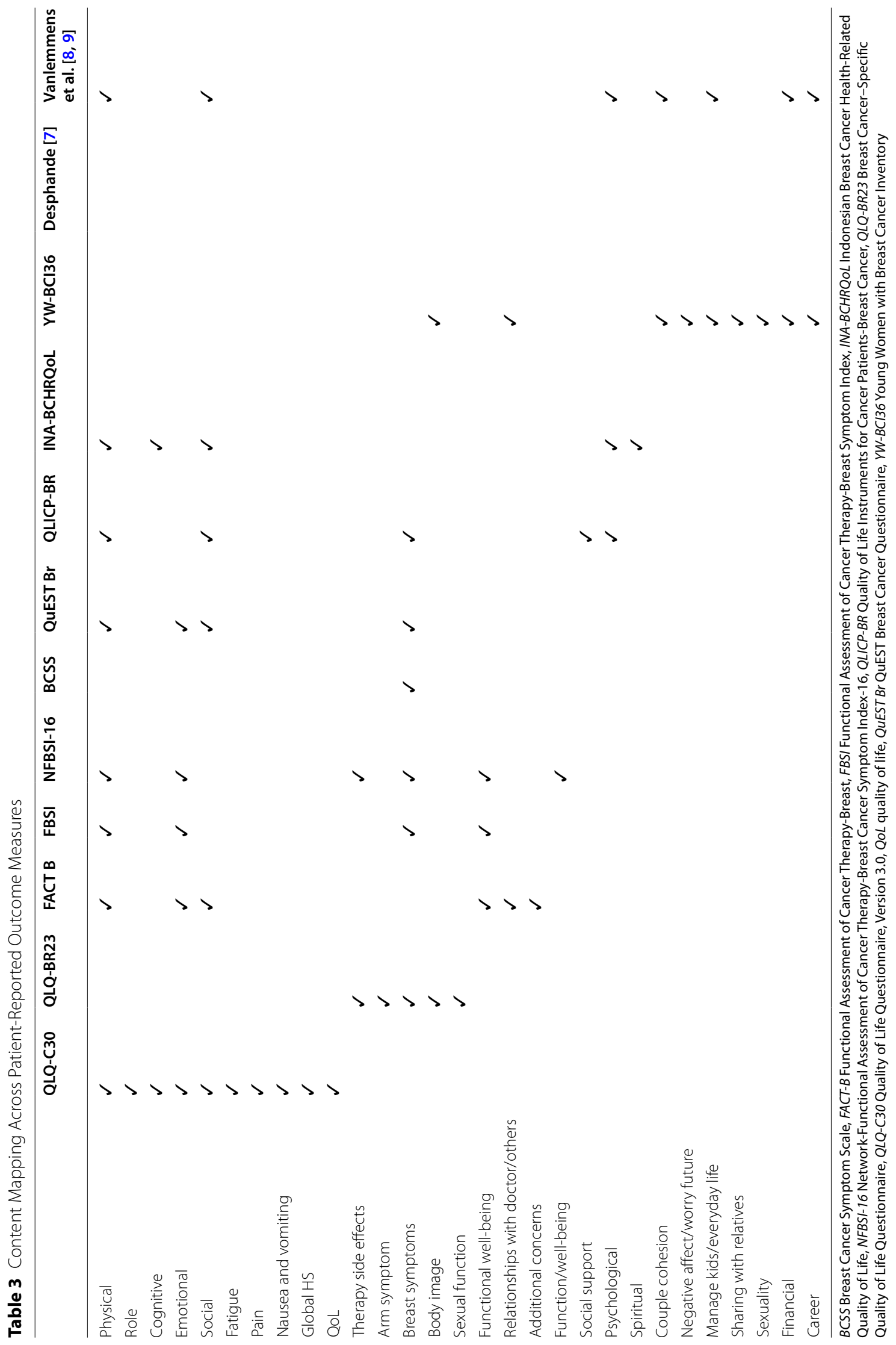




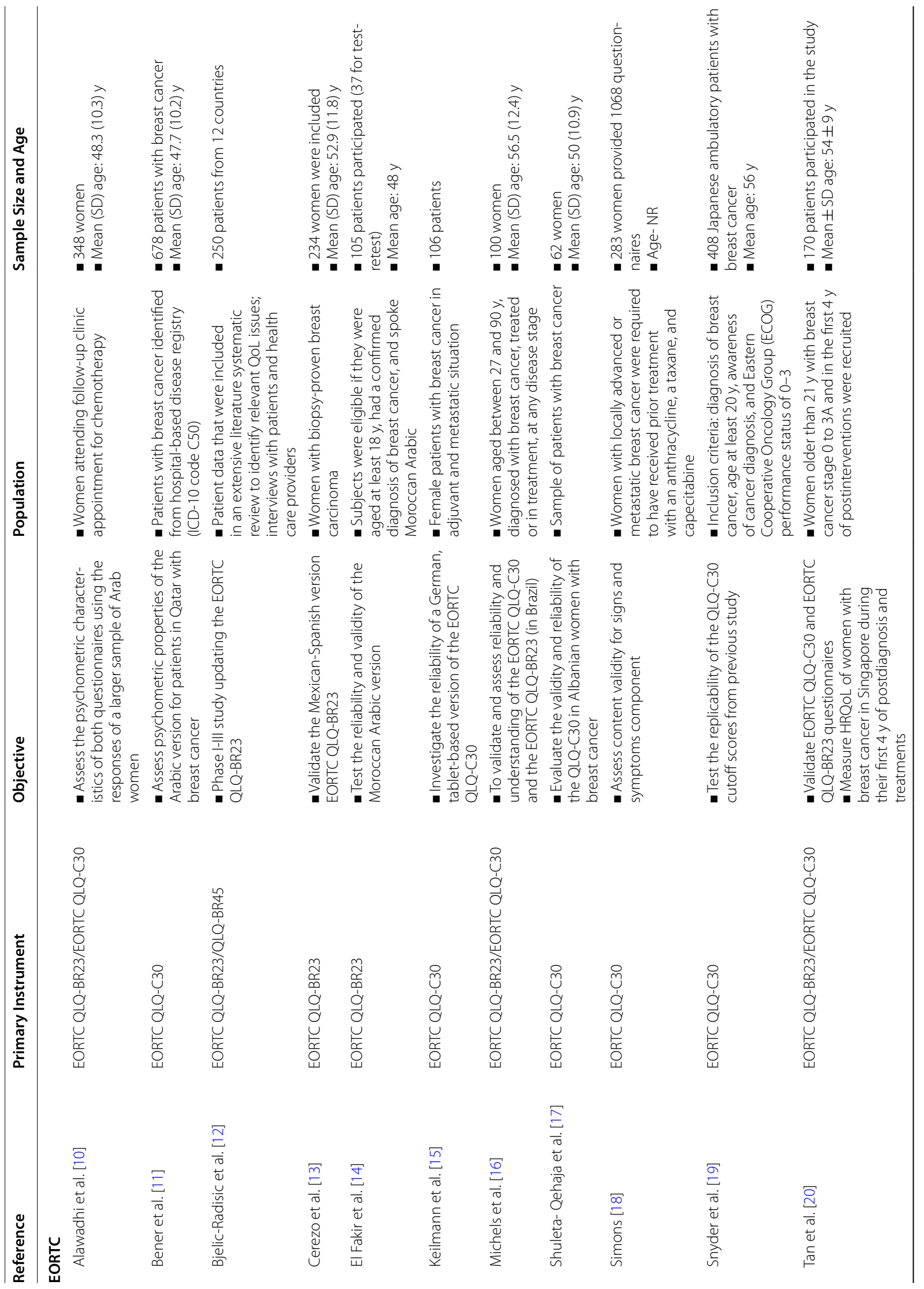




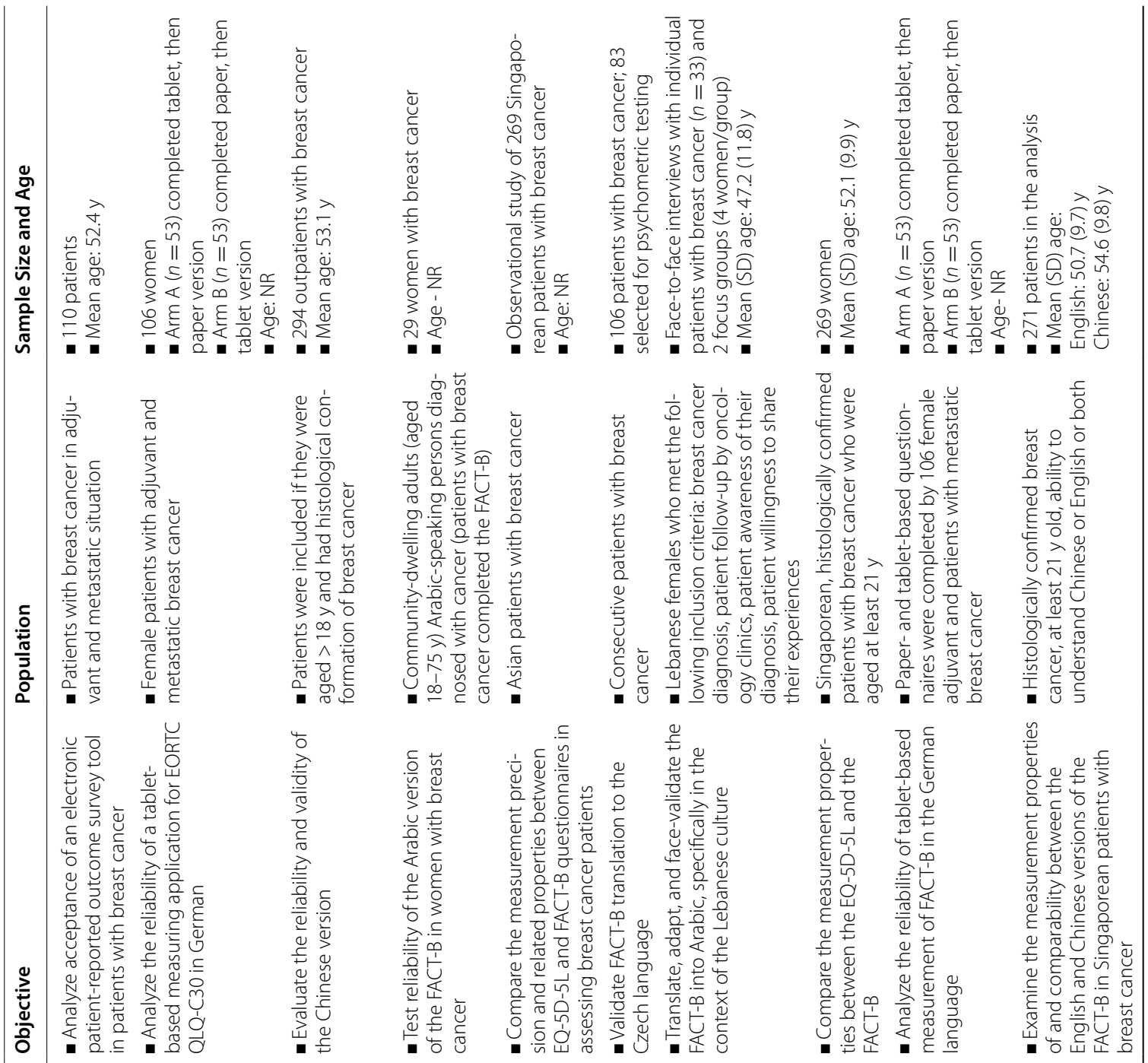

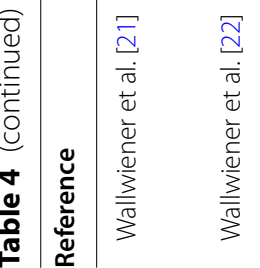

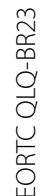

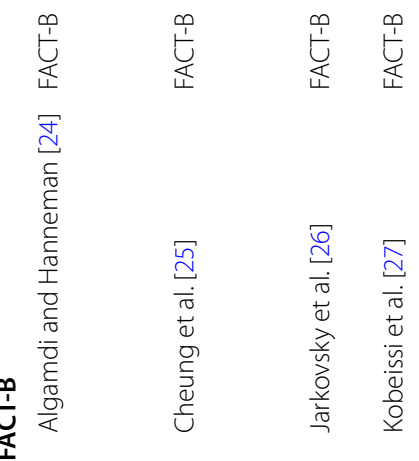

站是

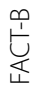

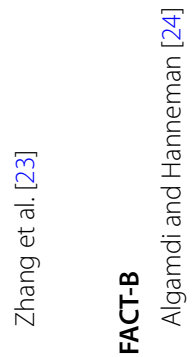

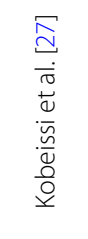

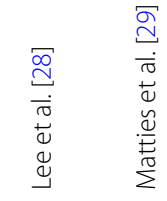

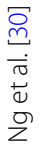



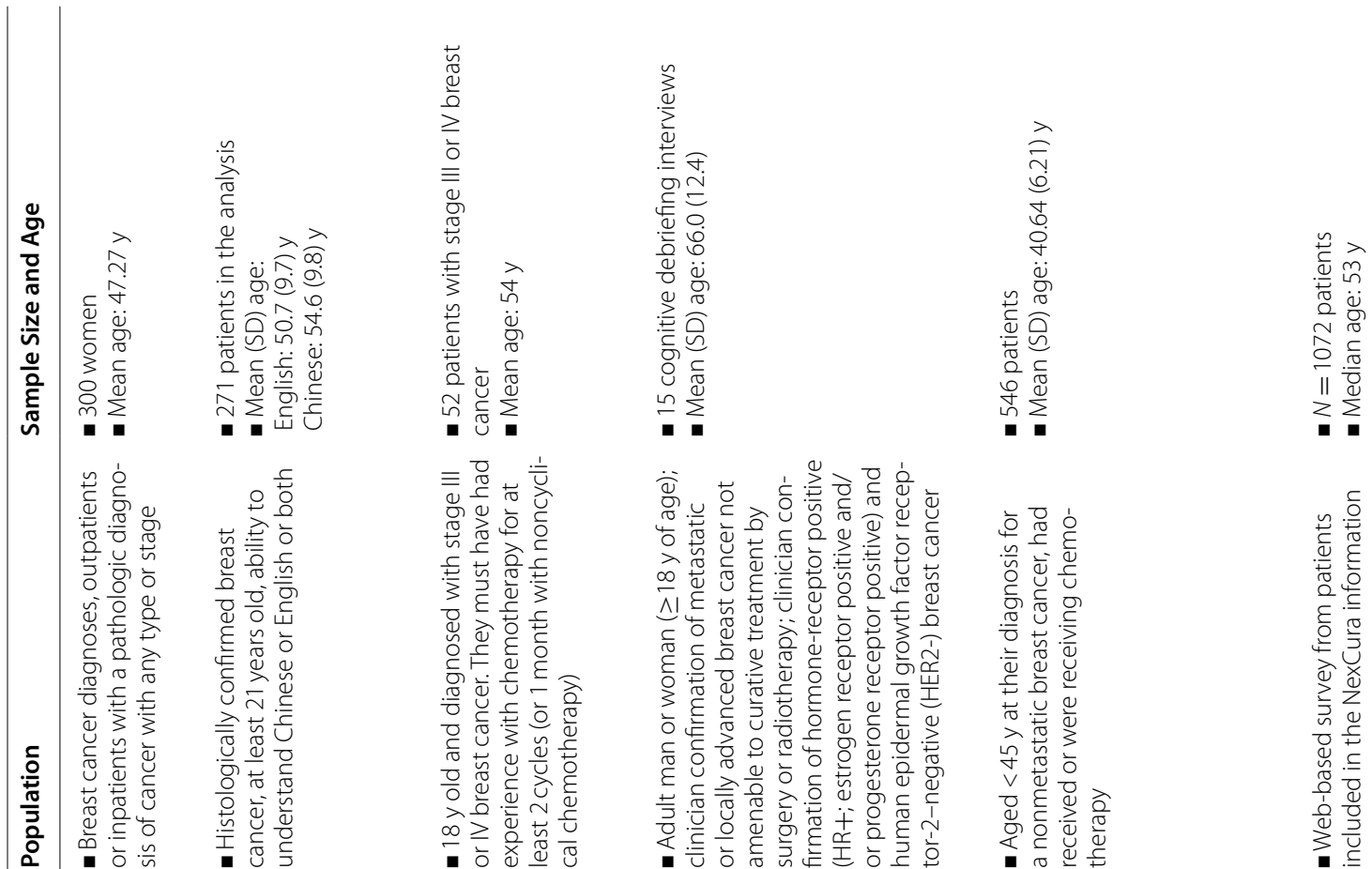

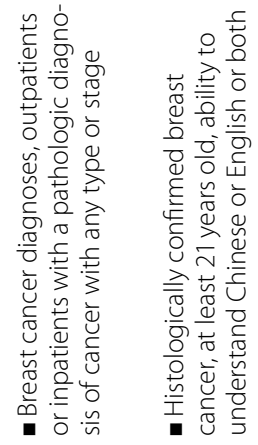

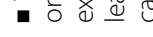

-
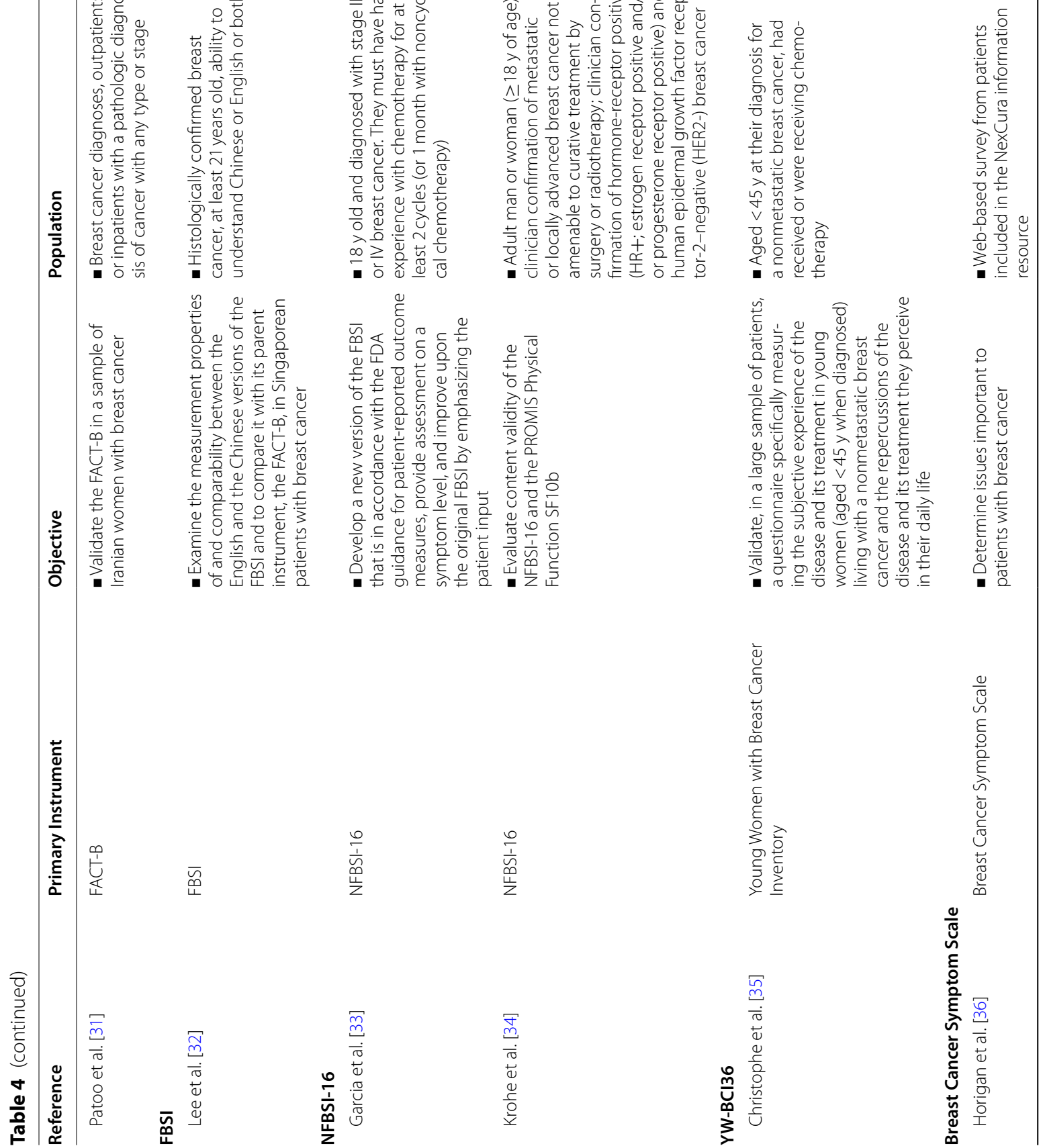

$\frac{v}{\frac{1}{5}}$
$\frac{0}{z}$
$\frac{u}{z}$
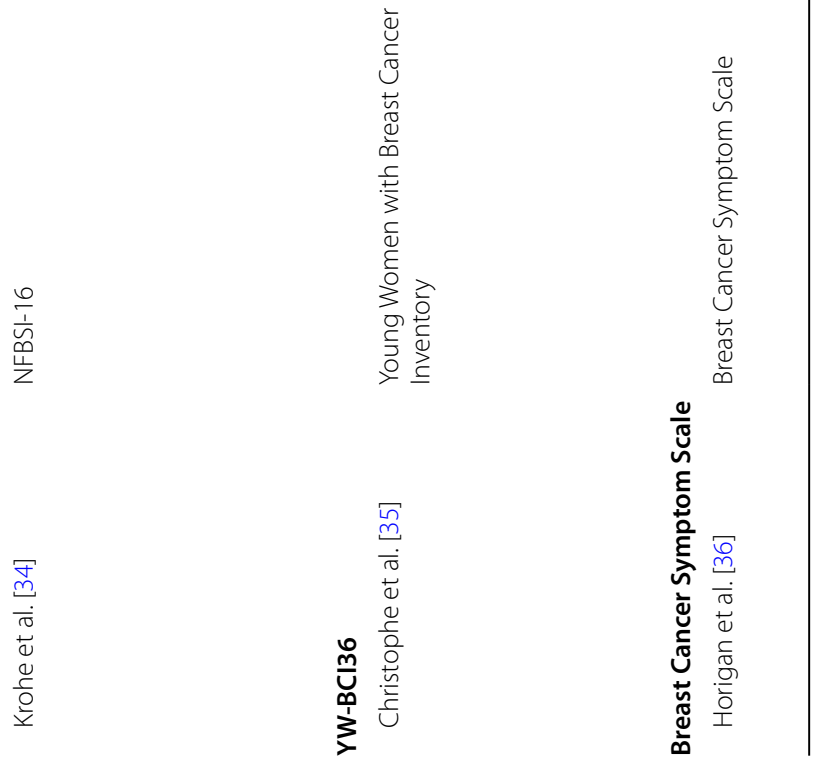


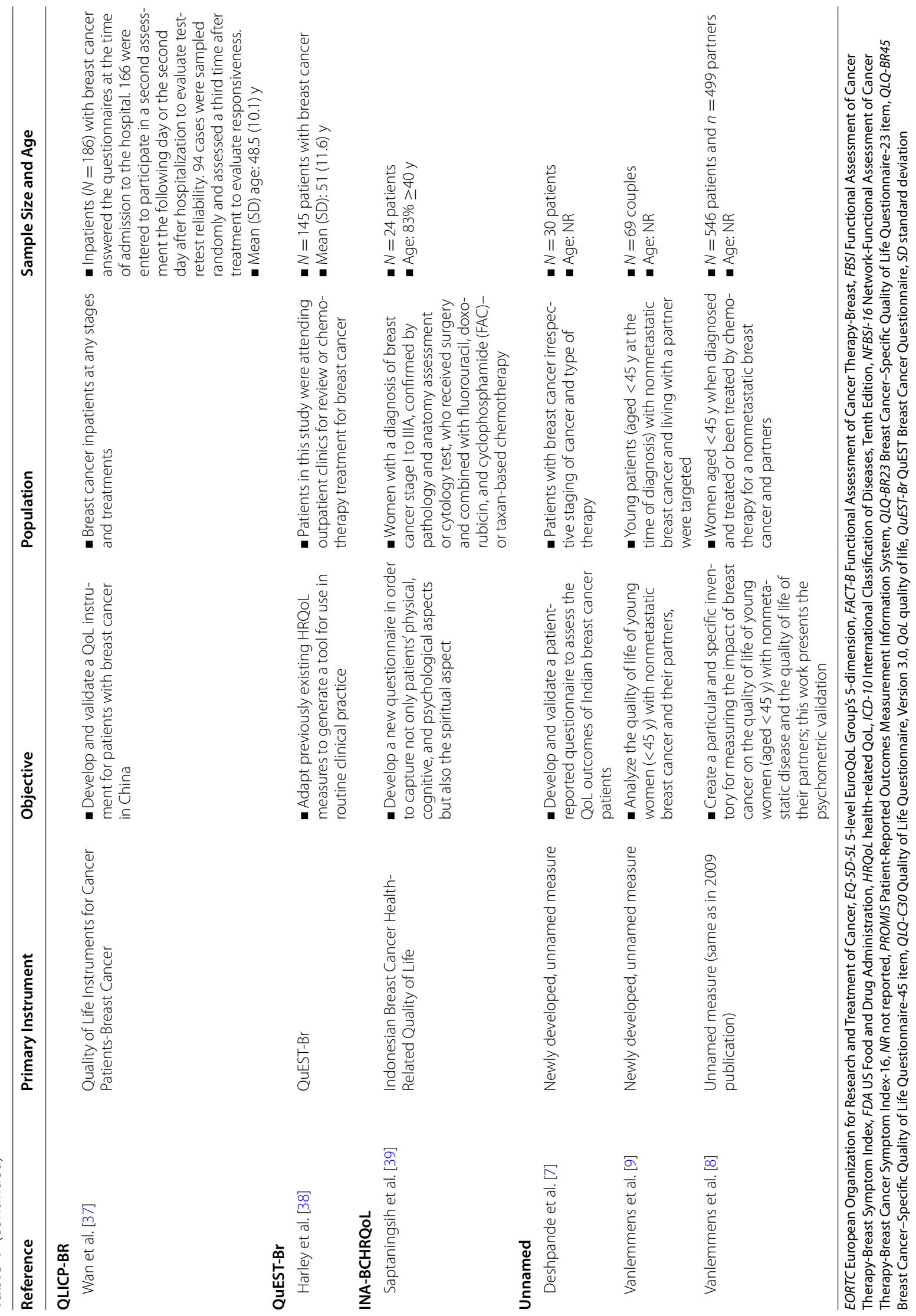


Administration of the measures via ePRO also has demonstrated reliability and validity $[15,21]$.

\section{FACT-B}

The majority of the FACT-B publications presented reliability and validity data for translations of the measure into Arabic [24], Persian [31], Czech [26], Lebanese Arabic [27], and Chinese [30] (Table 4). One publication presented data regarding the appropriateness of an ePRO application [29]. Two articles compared the properties of the FACT-B (disease-specific measure) with that of a general HRQoL measure, the EQ-5D [25, 28].

Internal consistency reliability (Cronbach alpha) and test-rest reliability (intraclass correlation coefficient) met accepted thresholds for the translations [24, 26, 31] (Table 5). Content validity was established in Lebanese Arabic translation [27]. Administration of the measure via ePRO was deemed acceptable [29].

\section{Other measures}

\section{FBSI and NFBSI-16}

The Chinese translation of the FBSI has demonstrated adequate test-retest reliability as well as known-group validity and convergent and divergent validity [32]. Garcia et al. [33] sought to develop a new version of the FBSI in accordance with US Food and Drug Administration guidance for PRO measures that provides assessment on a symptom level and improves upon the original FBSI by emphasizing input from patients. Specifically, 52 patients with breast cancer provided their top-priority symptoms/ concerns through open-ended interviews and symptom checklists. After patient input was reviewed, eight additional items were added to the original FBSI, creating the NFBSI-16. Conceptual relevance was supported for most items in the NFBSI-16 based on patients' reports of experiencing the concepts as part of their breast cancer experience [34].

\section{$Y W-B C I 36$}

Christophe et al. [35] developed a questionnaire specifically measuring the subjective experience of nonmetastatic breast cancer in young women (aged 45 years or younger when diagnosed), their perceptions regarding its treatment in their daily life, and the repercussions of the disease. Reliability and validity of the new measure were demonstrated (Table 5).

\section{BCSS}

Horigan et al. [36] conducted a large survey of registered patients with breast cancer to further document the content validity of the BCSS. Specifically, the patients were asked to rank 21 issues identified as important to them.
The nine highest ranked items include good QoL, maintaining independence, able to sleep, able to concentrate, perform normal activities, being fatigued, having depression, being anxious, and having pain. The five lowest ranked items include appetite, breast-specific issues, hot flashes, and sexuality. Ratings by breast cancer subset (newly diagnosed, on treatment, no evidence of disease, hormonal or nonhormonal treatment, metastatic disease, survivors) showed some differences compared with those by the whole group.

\section{QuEST-Br}

Harley et al. [38] adapted existing HRQoL instruments (EORTC measures) for use in routine clinical practice delivering outpatient chemotherapy for breast cancer. Methods followed the guidelines laid out by the EORTC Quality-of-Life Group for developing questionnaire modules [40]. Internal consistency reliability was $>0.70$ for the QuEST-Br scale [38].

\section{QLICP-BR}

Wan et al. [37] developed and validated a QoL instrument for patients with breast cancer in China. The measure was developed with particular attention to Chinese culture. For example, the family relationship and kinship play very important roles in daily life. Taoism and traditional medicine focus on good temper and high spirit. Good appetite, sleep, and energy are highly regarded in daily life, and food culture is very important [37]. The QLICP-BR was found to have adequate reliability and validity (Table 5).

\section{INA-BCHRQoL}

Saptaningsih et al. [39] developed a new measure to capture not only the physical, cognitive, and psychological aspects of patients but also the spiritual aspect. The questionnaire was developed in Indonesia and was designed to be culturally relevant (i.e., it included a spiritual domain, which is suitable for Indonesia, as it is a very religious country) to the breast cancer population in Indonesia. The INA-BCHRQoL was found to have adequate reliability and validity (Table 5).

\section{Unnamed measures}

Deshpande et al. [7] developed and validated a patientreported questionnaire to assess the QoL outcomes of patients with breast cancer in India. Reliability and content validity were demonstrated (Table 5).

Vanlemmens et al. [8, 9] developed and validated a particular and specific inventory for measuring the impact of breast cancer on the QoL of young women $(<45$ years of age) with nonmetastatic disease and the QoL of their partners. Reliability (internal consistency and test-retest) 


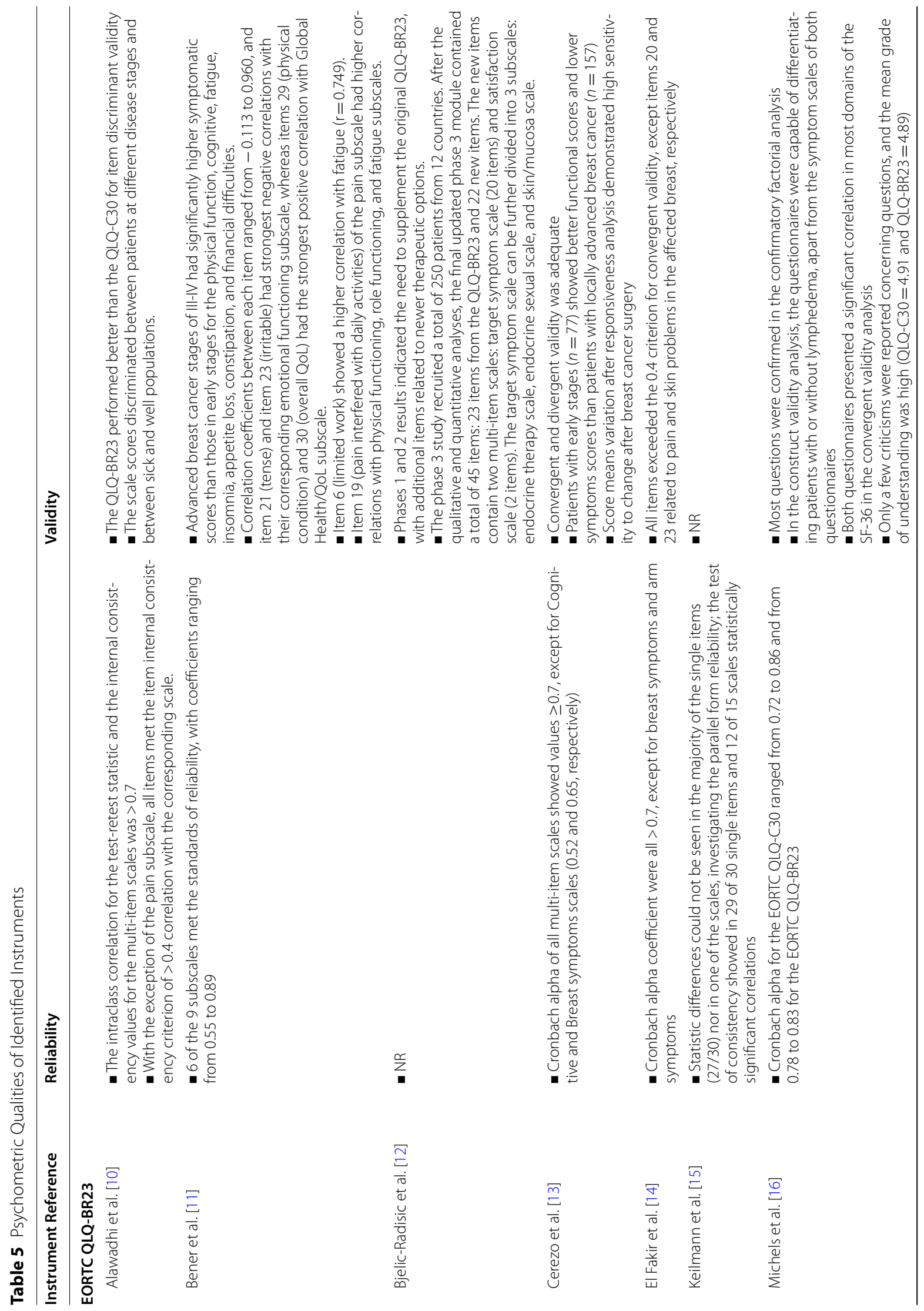




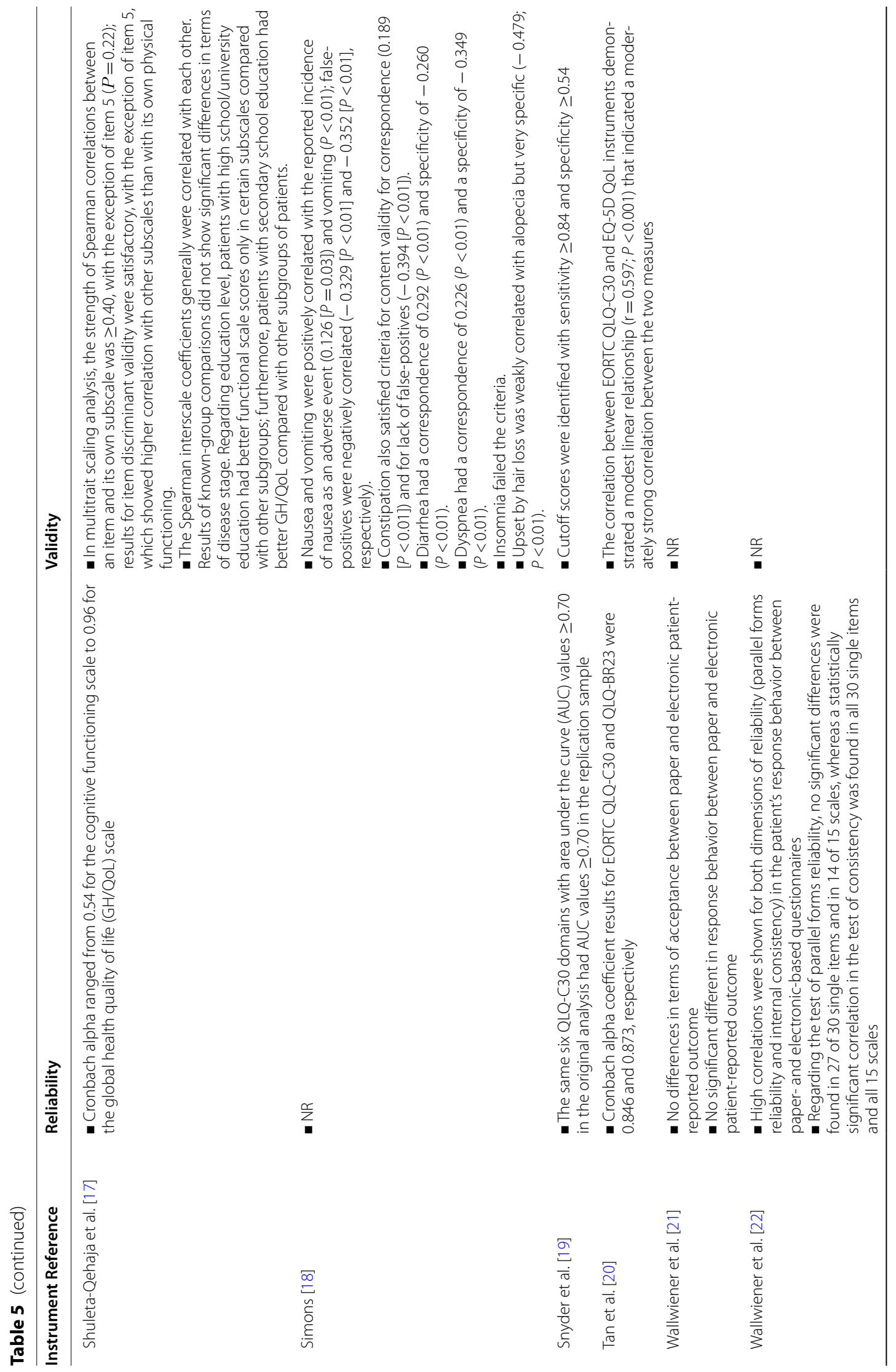




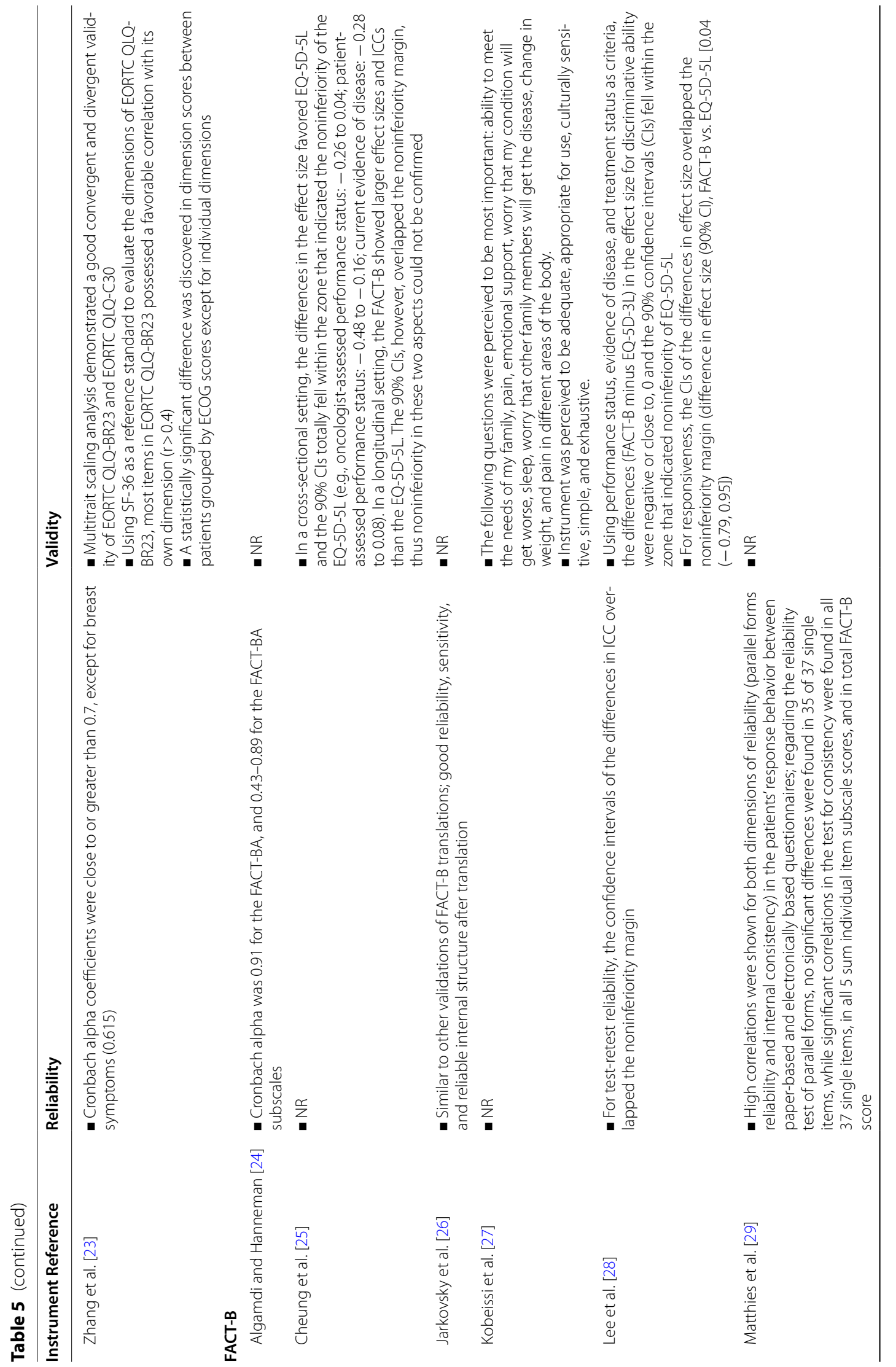




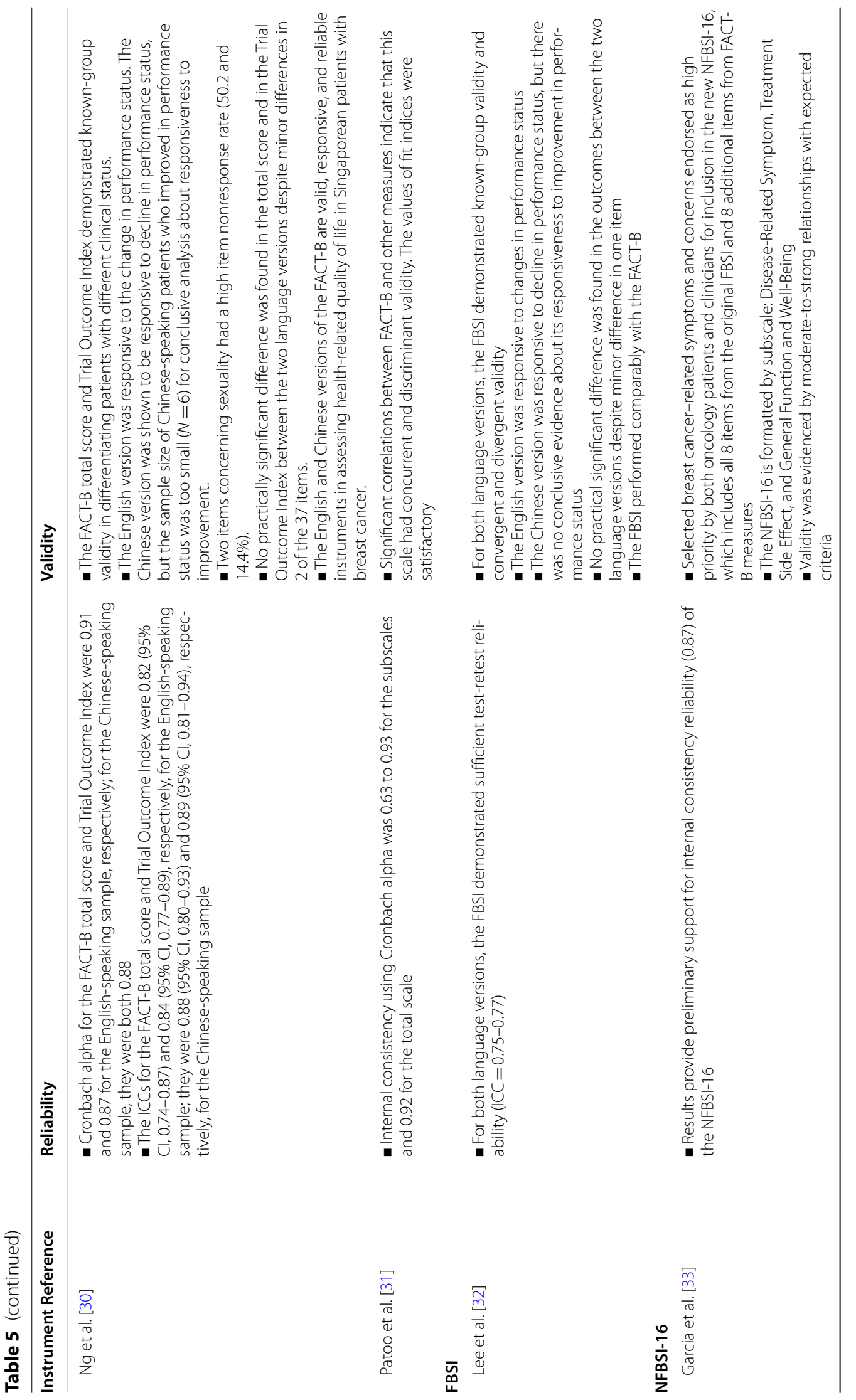




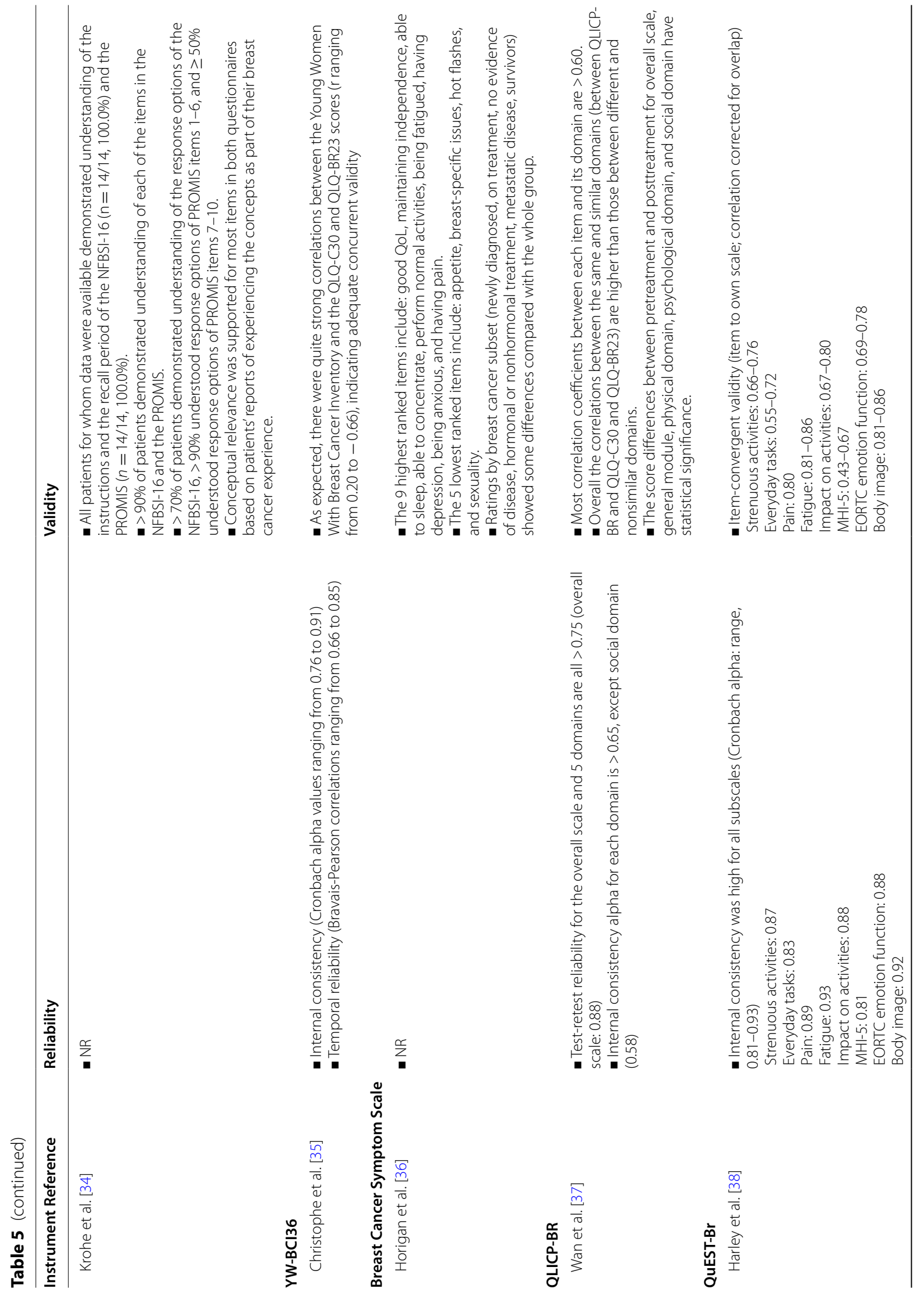




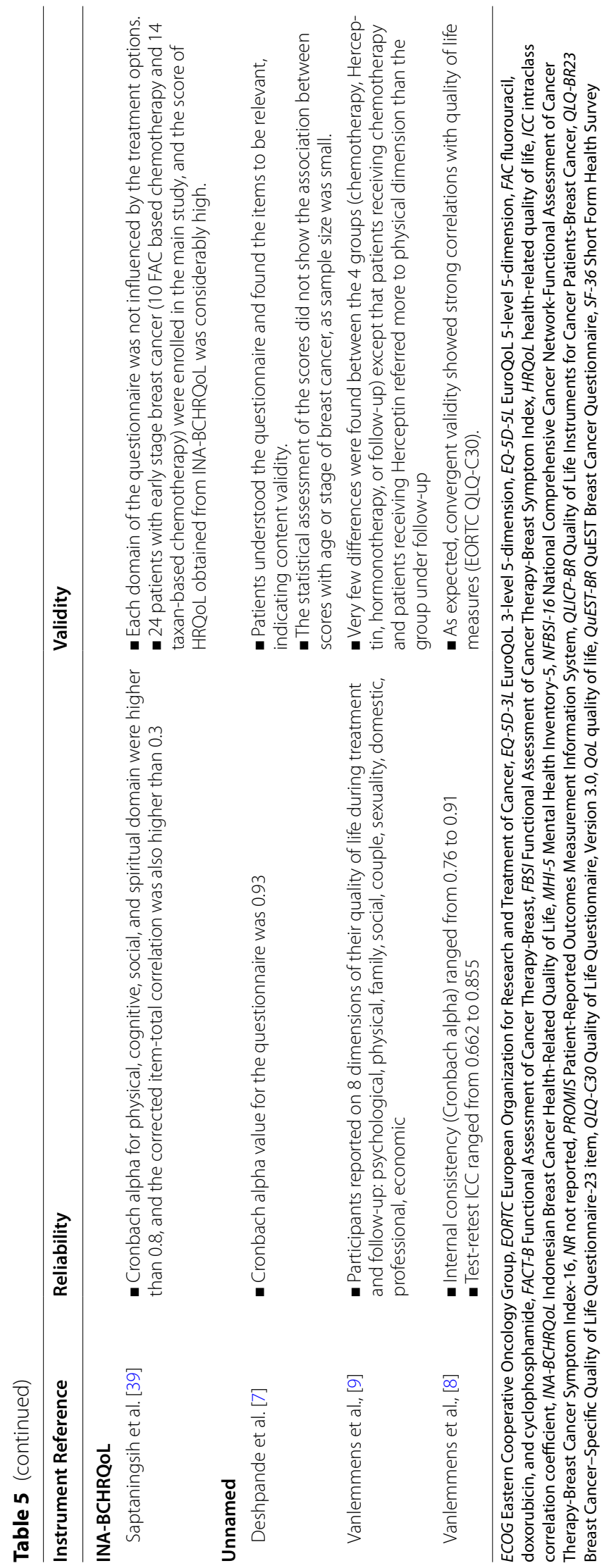


has been established. Convergent validity showed strong correlations with QoL measures (EORTC QLQ-C30) (Table 5).

\section{Discussion}

Understanding the effect of breast cancer treatment on a patient's HRQoL is a central clinical and research question. However, to accurately assess HRQoL, valid and reliable PROMs are needed: that is, PROMs with evidence of reliability, validity, and responsiveness in the population of interest (breast cancer). This review sought to identify disease-specific HRQoL measures with evidence of validation in the breast cancer population for potential use in patients underwent systemic treatment for breast cancer (excluding surgery and radiotherapy). In addition to the EORTC QLQ-C30, QLQ- BR23, and FACT-B, we identified an additional nine potential measures.

The identified PROMs vary in the content that they assess. For example, Vanlemmens and colleagues' measure for young women $(<45$ years of age $)$ is focused not only on the patient with breast cancer but also on her partner and their relationship (i.e., couple cohesion, managing children/everyday life) [9]. This measure also assesses impact of breast cancer on the woman's career and finances. Other than the YW-BCI36, none of the other instruments assess the impact of breast cancer on a woman's career or finances. Conversely, most do assess not only breast symptoms but also the physical and emotional/psychological impact of disease.

The YW-BCI36 [35] and the measure developed by Vanlemmens et al. [8,9] were both developed specifically for women $<45$ years old with breast cancer. Younger women with breast cancer have concerns (i.e., childcare, financial) that older women with breast cancer may not, thus these measures were developed specifically for this population. Several other PROMs were developed to meet a specific unmet need within regions (China, Indonesia, India) for measures that were culturally appropriate (QLICP-BC [37], INA-BCHRQoL [39], Indian breast cancer measure [7]). Given that these PROMs have been developed to be culturally relevant for a specific region/ population, they may not be appropriate for global studies.

Psychometric qualities that may be examined in the evaluation of an instrument may include acceptability, validity, reliability (including internal consistency and test-retest reliability), and responsiveness. When questionnaire responsiveness (the ability of a scale to detect significant change over time, assessed by comparing scores before and after an intervention of known efficacy) was examined on the basis of various methods, including $t$ tests, effect sizes, standardized response means, or responsiveness statistics, the information available was scarce.

The FACT-B and the QLQ-BR23 were designed for use in patients with breast cancer with a range of disease stages and undergoing different treatments. The EORTC QLQ-BR23 and the FACT-B are well developed instruments that have been extensively tested among patients with breast cancer. The FACT-B is shorter than the QLQBR23 and covers fewer symptoms and treatment-related side effects. This review has identified additional translations of the measures, providing further evidence of their validity. Internal consistency estimates of reliability were adequate for research purposes, although the internal consistency estimates were somewhat lower for the cognitive and breast symptoms scales. Further psychometric testing of the Breast Cancer-Specific Quality of Life Questionnaire-45 item (QLQ-BR45) may provide improved results. A recent publication [41] provides more detailed updates on the development of the QLQBR45. The QLQ-BR23 was one of the first disease-specific questionnaires developed in 1996 to assess QoL in patients with breast cancer. Given the effects of newer therapeutic options available since then, the developers believed it was evident that the original 23-item QLQBR23 may not be able to cover many important QoL issues and potential side effects of newer treatments. Therefore, the EORTC Quality of Life Group decided to update this module, eventually creating the QLQ-BR45. The development of the QLQ-BR45 involved a systematic literature review to identify relevant QOL issues for patients, interviews with patients and providers, and pretesting of a preliminary module in an international phase 3 study. Results of the literature review and discussions with patients and providers indicated that the original QLQ-BR23 inadequately covered concepts currently relevant to patients with breast cancer. Thus, new items were developed (added to the existing QLQ-BR23) and pretested in a multinational study, resulting in the QLQBR45, which is currently undergoing further psychometric testing.

Much of the additional psychometric data for the EORTC QLQ-C30, QLQ-BR23, and FACT-B are from new translations, further confirming the acceptability of these measures. Reliability of tablet or ePRO versions of the measures were also confirmed. New instruments were developed de novo in order to be considered more culturally relevant to patients in Asian countries. While these measures have demonstrated adequate internal consistency, test-retest and responsiveness data are lacking. 


\section{Conclusions}

Even though, historically there have been limited options for validated measures to assess HRQoL in breast cancer patients, a number of new options for assessing HRQoL in breast cancer population have been developed and validated in recent years. This review supports the reliability and validity of the EORTC QLQ-C30 and FACT-B; new translations and electronic versions of these measures further support their use for this population. Researchers should ensure that their selected PROMs are suitable for their target patient population, anticipated line of therapy, and the expected side effects of the therapies involved.

\begin{abstract}
Abbreviations
BCSS: Breast Cancer Symptom Scale; EORTC: European Organization for Research and Treatment of Cancer; ePRO: Electronic patient-reported outcome; FACT-B: Functional Assessment of Cancer Therapy-Breast; FBSI: Functional Assessment of Cancer Therapy-Breast Symptom Index; HRQoL: Health-related quality of life; INA-BCHRQoL: Indonesian Breast Cancer HealthRelated Quality of Life; NFBSI-16: National Comprehensive Cancer NetworkFunctional Assessment of Cancer Therapy-Breast Cancer Symptom Index-16; PICOS: Population, intervention, comparison, outcome, study type; PRO: Patient-reported outcome; PROM: Patient-reported outcome measure; QLICPBR: Quality of Life Instruments for Cancer Patients-Breast Cancer; QLQ-BR23: Breast Cancer-Specific Quality of Life Questionnaire-23 item; QLQ-BR45: Breast Cancer-Specific Quality of Life Questionnaire-45 item; QLQ-C30: Quality of Life Questionnaire, Version 3.0; QoL: Quality of life; QuEST-Br: QuEST Breast Cancer Questionnaire; YW-BCI36: Young Women with Breast Cancer Inventory.
\end{abstract}

\section{Acknowledgements}

Not applicable.

\section{Authors' contributions}

MS conceived of the study, contributed to the study design, secured funding, and critically revised the manuscript. MM designed the study; acquired, analyzed, and interpreted the data; provided study supervision; and drafted the manuscript. CC contributed to the study design; acquired, analyzed, and interpreted the data; and developed sections of the manuscript. ZI, NT, and $\mathrm{MDH}$ contributed to the study design and study concepts, interpreted the data, and critically revised the manuscript for important intellectual content. The author(s) read and approved the final manuscript.

\section{Funding}

The study was sponsored by Daiichi Sankyo Incorporation. However, the funding body played no role in the design of the study and collection, analysis, and interpretation of data and in writing the manuscript.

\section{Availability of data and materials}

All data generated or analyzed during this study are included in this published article [and its supplementary information files].

\section{Declarations}

Ethics approval and consent to participate

Not applicable.

\section{Consent for publication}

Not applicable.

\section{Competing interests}

Drs Salas, Islam, and Tu and Ms. Hackshaw El Khoury are employees of Daiichi Sankyo, Inc. are employees of RTI-Health Solutions.

\section{Author details}

${ }^{1}$ Epidemiology, Clinical Safety and Pharmacovigilance, Daiichi Sankyo, Inc., 211 Mount Airy Road, 1A-453, Basking Ridge, NJ 07920, USA. ²CCEB/CPeRT, University of Pennsylvania Perelman School of Medicine, Philadelphia, PA, USA. ${ }^{3}$ RTI Health Solutions, Ann Arbor, MI, USA. ${ }^{4}$ RTI Health Solutions, Research Triangle Park, NC, USA.

Received: 15 February 2021 Accepted: 24 December 2021

Published online: 15 January 2022

\section{References}

1. FDA. US Food and Drug Administration. Guidance for industry: patientreported outcome measures: use in medical product development to support labeling claims. 2009. Available at: https://www.fda.gov/media/ 77832/download. Accessed 7 Nov 2019.

2. Wilson IB, Cleary PD. Linking clinical variables with health-related quality of life: a conceptual model of patient outcomes. JAMA. 1995;273(1):59-65.

3. Bray F, Ferlay J, Soerjomataram I, Siegel RL, Torre LA, Jemal A. Global cancer statistics 2018: GLOBOCAN estimates of incidence and mortality worldwide for 36 cancers in 185 countries. CA Cancer J Clin. 2018:68(6):394-424.

4. Cardoso F, Costa A, Norton L, Senkus E, Aapro M, Andre F, et al. ESO-ESMO 2nd international consensus guidelines for advanced breast cancer (ABC2). Breast. 2014;23(5):489-502.

5. Beslija S, Bonneterre J, Burstein HJ, Cocquyt V, Gnant M, Heinemann V, et al. Third consensus on medical treatment of metastatic breast cancer. Ann Oncol. 2009;20(11):1771-85.

6. Nguyen J, Popovic M, Chow E, Cella D, Beaumont JL, Chu D, et al. EORTC QLQ-BR23 and FACT-B for the assessment of quality of life in patients with breast cancer: a literature review. J Comp Eff Res. 2015;4(2):157-66.

7. Deshpande P, Chittkathopottamal AN, Bommareddy LS, Mallasamy S. Development and validation of a patient-reported questionnaire to assess the quality of life outcomes of Indian breast cancer patients. Value Health. 2012;15(4):A236.

8. Vanlemmens L, Congard A, Antoine P, Fournier E, Lesur A, Loustalot C, et al. Construction of two quality of life questionnaires from young breast cancer patients and their partner. Cancer Res. 2013;73(24):3-09-07.

9. Vanlemmens L, Fournier E, Christophe V, Boinon D, Toudic-Emily F, Duffour $B$, et al. The impact of breast cancer on the quality of life of young women and their partners depending on the treatment in the period concerned. Psycho-Oncology. 2009;18:S149.

10. Alawadhi SA, Ohaeri JU. Validity and reliability of the European Organization for Research and Treatment in Cancer quality of life questionnaire (EORTC QLQ): experience from Kuwait using a sample of women with breast cancer. Ann Saudi Med. 2010;30(5):390-6.

11. Bener A, Alsulaiman R, Doodson L, El Ayoubi HR. An assessment of reliability and validity of the European Organization for Research and Treatment of cancer quality of life questionnaire C30 among breast cancer patients in Qatar. J Family Med Prim Care. 2017;6(4):824-31.

12. Bjelic-Radisic V, Bottomley A, Cardoso F, Cameron D, Brain E, Kuljanic K, et al. An international update of the EORTC questionnaire for assessing quality of life in breast cancer patients (EORTC QLQ-BC23) - EORTC QLQBR45. Ann Oncol. 2018;29:viii59-60.

13. Cerezo O, Onate-Ocana LF, Arrieta-Joffe P, Gonzalez-Lara F, Garcia-Pasquel MJ, Bargallo-Rocha E, et al. Validation of the Mexican-Spanish version of the EORTC QLQ-C30 and BR23 questionnaires to assess health-related quality of life in Mexican women with breast cancer. Eur J Cancer Care (Engl). 2012;21(5):684-91.

14. El Fakir S, Abda N, Bendahhou K, Zidouh A, Bennani M, Errihani H, et al. The European Organization for Research and Treatment of Cancer quality of life questionnaire-BR23 breast cancer-specific quality of life questionnaire: psychometric properties in a Moroccan sample of breast cancer patients. BMC Res Notes. 2014;7:53.

15. Keilmann L, Matthies L, Simoes E, Hartkopf AD, Sokolov AN, Walter CB, et al. Quality of life measurement in breast cancer patients: reliability of an ePRO tool using EORTC QLQ-C30. Eur J Obstet Gynecol Reprod Biol. 2019;234:e148-e9. 
16. Michels FA, Latorre Mdo R, Maciel MS. Validity, reliability and understanding of the EORTC-C30 and EORTC-BR23, quality of life questionnaires specific for breast cancer. Rev Bras Epidemiol. 2013;16(2):352-63.

17. Shuleta-Qehaja S, Sterjev Z, Shuturkova L. Evaluation of reliability and validity of the European Organization for Research and Treatment of Cancer Quality of Life Questionnaire (EORTC QLQ-C30, Albanian version) among breast cancer patients from Kosovo. Patient Prefer Adherence. 2015;9:459-65.

18. Simons WR. Content validity of signs and symptoms measures with the EORTC core module in women with locally advanced or metastatic breast cancer (MBC): a phase II trial with eribulin mesylate. J Clin Oncol. 2013;31(15_suppl):e17576-e.

19. Snyder CF, Blackford AL, Okuyama T, Akechi T, Yamashita H, Toyama T, et al. Using the EORTC-QLQ-C30 in clinical practice for patient management: identifying scores requiring a clinician's attention. Qual Life Res. 2013;22(10):2685-91.

20. Tan ML, Idris DB, Teo LW, Loh SY, Seow GC, Chia YY, et al. Validation of EORTC QLQ-C30 and QLQ-BR23 questionnaires in the measurement of quality of life of breast cancer patients in Singapore. Asia Pac J Oncol Nurs. 2014;1 (1):22-32.

21. Wallwiener M, Simoes E, Hartkopf AD, Taran FA, Keilmann L, Sickenberger $\mathrm{N}$, et al. Reliability and acceptance of e-based survey instruments for measuring patient reported outcomes (PRO) in breast cancer patients: first results of the ePROCOM study. Cancer Res. 2017;77(4):3-11-05.

22. Wallwiener M, Matthies L, Simoes E, Keilmann L, Hartkopf AD, Sokolov AN, et al. Reliability of an e-PRO tool of EORTC QLQ-C30 for measurement of health-related quality of life in patients with breast cancer: prospective randomized trial. J Med Internet Res. 2017;19(9):e322.

23. Zhang $Z$, Zhang $X$, Wei $L$, Lin $Y, W u ~ D$, Xie $S$, et al. Questionnaire to assess quality of life in patients with breast cancer - validation of the Chinese version of the EORTC QLQ-BR 53. Breast. 2017;32:87-92.

24. Algamdi MM, Hanneman SK. Reliability estimates for the Arabic versions of the cancer behavior inventory-brief and the functional assessment of cancer therapy-breast. J Nurs Meas. 2016;24(3):388-98.

25. Cheung YB, Lee CF, Luo N, Ng R, Wong NS, Yap YS, et al. Comparison of the measurement properties between the 5-level euroqol group's 5-dimension (EQ-5D-5I) questionnaire and the functional assessment of cancer therapy-breast (FACT-B) in Asian breast cancer patients. Value Health. 2012;15(7):A605

26. Jarkovský J, Skřivanová K, Benešová K, Nedvěd J, Brančíková D, Peterková $\mathrm{H}$, et al. Validation of the Czech version of the FACT-B scale for measuring quality of life in breast cancer patients. Klinicka. Onkologie. 2016;29:2S62.

27. Kobeissi L, Saad MA, Doumit M, Mohsen R, Salem Z, Tfayli A. Face validity of the functional assessment of cancer therapy-breast symptom index (FACT- B) into formal Arabic. Middle East J Cancer. 2014;5(3):151-65.

28. Lee CF, Luo N, Ng R, Wong NS, Yap YS, Lo SK, et al. Comparison of the measurement properties between a short and generic instrument, the 5-level EuroQoL Group's 5-dimension (EQ-5D-5L) questionnaire, and a longer and disease-specific instrument, the functional assessment of cancer therapy-breast (FACT-B), in Asian breast cancer patients. Qual Life Res. 2013;22(7):1745-51.

29. Matthies LM, Taran FA, Keilmann L, Schneeweiss A, Simoes E, Hartkopf AD, et al. An electronic patient-reported outcome tool for the FACT-B (functional assessment of cancer therapy-breast) questionnaire for measuring the health-related quality of life in patients with breast cancer: reliability study. J Med Internet Res. 2019;21(1):e10004.

30. Ng R, Lee CF, Wong NS, Luo N, Yap YS, Lo SK, et al. Measurement properties of the English and Chinese versions of the functional assessment of cancer therapy-breast (FACT-B) in Asian breast cancer patients. Breast Cancer Res Treat. 2012;131(2):619-25.

31. Patoo M, Allahyari AA, Moradi AR, Payandeh M. Persian version of functional assessment of cancer therapy- breast (FACT-B) scale: confirmatory factor analysis and psychometric properties. Asian Pac J Cancer Prev. 2015;16(9):3799-803.

32. Lee CF, Ng R, Wong NS, Luo N, Yap YS, Lo SK, et al. Measurement properties of the eight-item abbreviated functional assessment of cancer therapy--breast symptom index and comparison with its 37-item parent measure. J Pain Symptom Manag. 2013;45(4):782-91.

33. Garcia SF, Rosenbloom SK, Beaumont JL, Merkel D, Von Roenn JH, Rao D, et al. Priority symptoms in advanced breast cancer: development and initial validation of the National Comprehensive Cancer Network-Functional
Assessment of Cancer Therapy-Breast Cancer Symptom Index (NFBSI-16). Value Health. 2012;15(1):183-90.

34. Krohe M, Tang DH, Klooster B, Revicki D, Galipeau N, Cella D. Content validity of the national comprehensive cancer network - functional assessment of cancer therapy - breast cancer symptom index (NFBSI16) and patient-reported outcomes measurement information system (PROMIS) physical function short form with advanced breast cancer patients. Health Qual Life Outcomes. 2019;17(1):92.

35. Christophe V, Duprez C, Congard A, Antoine P, Lesur A, Fournier E, et al. The subjective experience of young women with non-metastatic breast cancer: the young women with breast cancer inventory. Health Qual Life Outcomes. 2015;3(13):73.

36. Horigan JL, Gralla RJ, Davis BJ, Hollen PJ, Petersen JA, Burg K, et al. Determining issues of importance for patients with breast cancer: results of a web-based study in 1,072 patients to enhance the content validity for the development of a new health-related quality of life (QL) instrument, the breast cancer symptom scale (BCSS). J Clin Oncol. 2009;27(15):e20615.

37. Wan C, Yang Z, Tang X, Zou T, Chen D, Zhang D, et al. Development and validation of the system of quality of life instruments for cancer patients: breast cancer (QLICP-BR). Support Care Cancer. 2009;17(4):359-66.

38. Harley C, Takeuchi E, Taylor S, Keding A, Absolom K, Brown J, et al. A mixed methods approach to adapting health-related quality of life measures for use in routine oncology clinical practice. Qual Life Res. 2012;21(3):389-403.

39. Saptaningsih AB, Setiawan D, Rivany R, Aryandono T, Atthobari J, Dwiprahasto I. The development of quality of life questionnaire for Indonesian breast cancer patients: INA-BCHRQoL. Asian Pac J Cancer Prev. 2018;19(5):1269-75.

40. Blazeby J, Sprangers M, Cull A, Groenvold M, Bottomley A. Guidelines for developing questionnaire modules: EORTC quality of life group. EORTC. 2002. https://www.eortc.org/app/uploads/sites/2/2018/02/guidelines for_developing_questionnaire-_final.pdf. Accessed Jan 2022.

41. Bjelic-Radisic V, Cardoso F, Cameron D, Brain E, Kuljanic K, da Costa RA, et al. An international update of the EORTC questionnaire for assessing quality of life in breast cancer patients: EORTC QLQ-BR45. Ann Oncol. 2020;31(2):283-8.

\section{Publisher's Note}

Springer Nature remains neutral with regard to jurisdictional claims in published maps and institutional affiliations.

Ready to submit your research? Choose BMC and benefit from:

- fast, convenient online submission

- thorough peer review by experienced researchers in your field

- rapid publication on acceptance

- support for research data, including large and complex data types

- gold Open Access which fosters wider collaboration and increased citations

- maximum visibility for your research: over 100M website views per year

At BMC, research is always in progress.

Learn more biomedcentral.com/submissions 